\title{
O ensino-aprendizagem da anatomia humana: avaliação do desempenho dos alunos após a utilização de mapas conceituais como uma estratégia pedagógica
}

\author{
The teaching and learning of human anatomy: the assessment \\ of student performance after the use of concept maps \\ as a pedagogical strategy
}

\author{
Giselle Foureaux ${ }^{1}$. Marcos Augusto de Sá ${ }^{1}$. \\ Luana Pereira Leite Schetino ${ }^{2}$. Leonor Bezerra Guerra ${ }^{1}$. \\ Janice Henriques da Silva ${ }^{1}$
}

\begin{abstract}
Resumo: O objetivo deste estudo foi implementar e avaliar o impacto da elaboração de Mapas Conceituais (MC) como estratégia pedagógica no ensino-aprendizagem da Anatomia Humana, uma das disciplinas do curso de Fisioterapia da Universidade Federal de Minas Gerais. Participaram do estudo 298 alunos regularmente matriculados, ao longo de seis semestres. A análise das médias das notas finais dos alunos, anteriores à ampliação do projeto dos $\mathrm{MC}$, demonstrou decréscimo dessas médias ao longo dos semestres, o que foi revertido quando o projeto de ensino de MC foi implementado sistematicamente. A implementação dos MC também foi capaz de promover uma redução significativa no índice de reprovação. Assim, concluímos que o uso de MC parece ter contribuído para melhorar o desempenho dos alunos e também o índice de aprovação na disciplina de Anatomia Humana, principalmente após a sistematização do seu uso através do Projeto de Ensino apoiado pela Pró-Reitoria de Graduação da Instituição.
\end{abstract}

Palavras-chave: Mapas conceituais. Anatomia humana. Ensino superior. Ensino e aprendizagem. Ferramenta didática.

\begin{abstract}
The aim of this study was to implement and evaluate the impact of the development of Concept Maps (MC), as a pedagogical strategy in teaching of Human Anatomy, one of the course subjects of Physical Therapy, from Federal University of Minas Gerais (UFMG). A total of 298 students, enrolled regularly, participated of the study over six semesters. The mean analysis of the final scores of the students, prior to the expansion of the MC Project, showed decrease of average score over the semester, which was reversed when the MC were implemented systematically. The implementation of MC were also capable of promoting a significant reduction in the failure rate. Thus, we conclude that the use of MC seems to have contributed to improving student performance and also the approval rating in the discipline of Anatomy, especially after the systematization of its use by the Teaching Project supported by the institution.
\end{abstract}

Keywords: Concept maps. Human anatomy. Higher education. Teaching and learning. Methodology of teaching.

\footnotetext{
${ }^{1}$ Universidade Federal de Minas Gerais (UFMG), Instituto de Ciências Biológicas, Departamento de Morfologia, Belo Horizonte, MG, Brasil. Orcid: <https://orcid.org/0000-0001-7463-6368>. E-mail: <gifoureaux@icb.ufmg.br> . ${ }^{2}$ Universidade Federal dos Vales do Jequitinhonha e Mucuri (UFVJM), Faculdade de Medicina, Diamantina, MG, Brasil.
} 


\section{Introdução}

Nas últimas décadas, o ensino da Anatomia tem passado por mudanças estruturais, em parte, devido às reformas curriculares dos cursos da área da saúde, necessárias para o enquadramento nas novas diretrizes curriculares para os cursos de graduação (FORNAZIERO et al., 2010). Mas também, e principalmente, para acompanhar a evolução didático-pedagógica relacionada, especificamente dentro do contexto da Anatomia, a diversos fatores: (1) avanços da tecnologia digital, incluindo os avanços das imagens digitalizadas que permitem visualização de estruturas em 3D; (2) dificuldade de obtenção de cadáveres para dissecação devido a uma maior fiscalização da origem dos corpos; (3) aumento do número de alunos nas disciplinas de anatomia; (4) redução do tempo que o aluno dispende trabalhando com as mesmas estruturas (decorrentes dos aspectos mencionados nos itens 2 e 3), o que facilitaria a consolidação de memória; etc.

Em outras palavras, se por um lado, algumas mudanças têm facilitado o estudo da Anatomia, como o caso dos avanços da tecnologia digital; por outro, outras mudanças têm dificultado a aprendizagem da Anatomia. Consequentemente, mesmo diante de mudanças que pretendem contribuir para melhorar a formação acadêmica, ainda se observa um rendimento global aquém do esperado, o que culmina em um aumento do índice de reprovação e também no aumento da evasão (DIPLOMAÇÃO..., 1996; LOBO, 2012; PRIM; FÁVERO, 2013). Um estudo realizado na Universidade Federal de Minas Gerais (UFMG) em 2003, interessado nas razões da evasão nos cursos de graduação, demonstrou alta taxa de reprovação e baixo rendimento, principalmente nas disciplinas de primeiros períodos, com uma implicação direta no percentual de evasão da universidade (BRAGA; PEIXOTO; BOGUTCHI, 2003). Esse baixo rendimento pode estar relacionado a vários fatores, dentre eles, a possibilidade de utilizar apenas metodologias tradicionais e convencionais que não mais atendem o perfil do atual acadêmico.

Numa perspectiva construtivista, o aprendizado envolve a construção ativa do conhecimento e a formação de capacidades intelectuais pelo próprio estudante (ALLEN; TANNER, 2005). Um princípio fundamental para a aprendizagem seria o aluno construir sua própria compreensão de conceitos, relações e procedimentos (BRANSFORD; BROWN; COCKING, 1999). Esse princípio fundamenta a Teoria de Aprendizagem Significativa, de David Ausubel, aquela em que ideias expressas simbolicamente interagem de maneira substantiva e não arbitrária com aquilo que o aprendiz já sabe. Substantiva quer dizer não literal, não ao pé da letra; e não arbitrária significa que a interação não é com qualquer ideia prévia, mas sim com algum conhecimento especificamente relevante já existente na estrutura cognitiva do sujeito que aprende (MOREIRA, 2012). Portanto, a aprendizagem é dita significativa quando a assimilação de novas proposições ocorre por meio de estruturas cognitivas pré-existentes, facilitando o estabelecimento de conceitos sólidos (GOMES et al., 2011).

Nesse cenário, os Mapas Conceituais (MC), idealizados por Novak e Gowin, surgem como uma ferramenta com potencial para favorecer a aprendizagem significativa, uma vez que esta depende da captação de significados, um processo que envolve uma negociação de significados cognitivos entre docente e discente e pode ser longo. Os MC, principalmente quando são desenvolvidos em grupos, são instrumentos úteis nesse processo de negociação. Os significados podem ser compartilhados, discutidos, negociados e sujeitos a consenso tanto entre discentes quanto entre discentes e docentes (NOVAK; GOWIN, 1984). 
Os MC são diagramas que indicam relações entre conceitos incluídos numa estrutura hierárquica de proposições (RUIZ-MORENO et al., 2007). Tais mapas estão sendo cada vez mais utilizados nas mais diversas áreas do conhecimento. Eles constituem potente ferramenta de ensino e/ou de aprendizagem para refletir o conhecimento essencial daquilo que está expresso em um texto. Por meio dos MC, o aprendiz exterioriza conceitos e relações entre eles, presentes em sua estrutura cognitiva. Os MC têm potencial para favorecer a aprendizagem significativa de forma mais eficaz que as abordagens tradicionais de ensino (CAÑA et al., 2003; NOVAK, 2003; NOVAK; WANDERSEE, 1990; WILLERMAN, 1991). Além disso, a representação gráfica de um MC utilizado para a comunicação de conteúdos complexos é cognitivamente mais efetiva do que um texto, pois o processamento mental de imagens parece ser menos exigente que o processamento mental de um texto (VEKIRI, 2002).

Nesse sentido, professores podem estimular a aprendizagem significativa utilizando estratégias que propiciem ao aluno a busca de relações entre o conhecimento existente na estrutura cognitiva e os novos conhecimentos (NOVAK, 2003). A Anatomia Humana tem um conteúdo vasto, organizado por conceitos a serem memorizados e associados entre si, para que seja um conhecimento útil ao estudante ou profissional. Nesse contexto, os MC parecem ser um recurso pedagógico de grande valia para a Anatomia.

Assim, o objetivo deste trabalho foi implementar e avaliar o impacto da elaboração de MC como estratégia pedagógica no ensino-aprendizagem da disciplina Anatomia Humana aplicada à Fisioterapia da UFMG.

\section{Utilização dos Mapas Conceituais no ensino-aprendizagem da Anatomia Humana}

A Anatomia Humana é uma disciplina de caráter básico na formação do profissional da área da saúde e constitui, juntamente com a Embriologia, Citologia e Histologia, as Ciências Morfológicas ou Morfologia. Para compreender alguns aspectos que motivaram a adoção de uma estratégia alternativa, como recurso pedagógico para contribuir com o processo de assimilação e associação de conhecimentos inerentes à Anatomia Humana, é oportuno traçar um pequeno panorama histórico.

Anatomia é uma ciência que tem sua história interligada à história da medicina. No entanto, há indícios de que sua origem tenha sido em tempos remotos, quando o aprimoramento de técnicas para caçar animais e a seleção de suas partes destinadas ao consumo e rejeito exigiam certo conhecimento anatômico (PIAZZA; CHASSOT, 2011). O período histórico mais conhecido da Anatomia (MOSLEY; LYNCH, 2011) prossegue em 384 a.C., quando Aristóteles nomeou a principal artéria do corpo humano, a aorta. Um pouco mais tarde (130 d.C.-201 d.C.) Galeno também contribuiu com essa ciência através de observações relacionadas à anatomia de babuínos e porcos, numa época na qual a dissecação de humanos era desencorajada. Durante o Renascimento, Leonardo da Vinci (1452-1519), destacando-se tanto na arte quanto na Anatomia, criou o símbolo da Anatomia, o Homem Vitruviano. O primeiro Tratado de Anatomia foi publicado em 1543 por Andreas Vesalius que roubava cadáveres de criminosos e dissecava todas as estruturas, estudando-as minuciosamente. Assim, localizou os principais órgãos, nervos e músculos do corpo humano, iniciando então, o estudo sistematizado da Anatomia Humana (MOSLEY; 
LYNCH, 2011). A Anatomia, como descrita por Dante Bertelli em 1932, tornou-se o fundamento de todas as outras ciências médicas, sem a qual essas não poderiam subsistir (DI DIO, 1998).

Ao longo do tempo, anatomistas de diferentes partes do mundo, sem ainda convencionar uma nomenclatura, foram descrevendo e nomeando uma mesma estrutura com termos diversos, o que resultou em múltiplas denominações de mesmas estruturas anatômicas. Ainda após a adoção de uma única Terminologia Anatômica, enumeram-se, aproximadamente, seis mil nomes para estruturas macroscópicas do corpo (FEDERATIVE COMMIT'TEE ON ANATOMICAL TERMINOLOGY, 1998). O desenvolvimento histórico da Anatomia contribui para que seu estudo na atualidade implique o conhecimento e apropriação - por estudantes e profissionais, e conforme especificidade da área - de elevado número de vocábulos para descrição das várias estruturas que constituem o corpo humano.

Consequentemente, se por um lado a Anatomia Humana desperta grande interesse entre os acadêmicos dos cursos das áreas da saúde; por outro, desperta receio, devido às peculiaridades de aprendizagem, que requer aquisição de um novo vocabulário, atribuição de significado às novas palavras, estabelecimento de associação entre elas e incorporação funcional do novo léxico à vida acadêmica e/ou profissional do indivíduo. Promover essa aprendizagem requer mediação eficiente do professor, que envolve a utilização de estratégias e materiais potencialmente significativos, e predisposição para aprender por parte do aprendiz (MOREIRA, 2012), sendo esses princípios importantes para o desenvolvimento da aprendizagem significativa. A primeira condição implica que o material de aprendizagem tenha significado lógico, e que o aprendiz tenha em sua estrutura cognitiva ideias-âncora relevantes com as quais esse material pode ser relacionado. A segunda condição envolve a predisposição do aprendiz de querer relacionar os novos conhecimentos de forma não arbitrária e não literal a seus conhecimentos prévios. E essa predisposição para aprender não se trata apenas de motivação ou de gostar de determinada disciplina, mas de ter predisposição para relacionar interativamente os novos conhecimentos à estrutura cognitiva prévia, modificando-a, elaborando-a e dando significados a esses conhecimentos (MOREIRA, 2012). Nesse contexto, a equipe do setor de Anatomia do Departamento de Morfologia da Universidade Federal de Minas Gerais (UFMG) tem trabalhado na inserção dos MC como estratégia para potencializar o ensino-aprendizagem dessa disciplina, ofertada no ciclo básico dos cursos da saúde.

Outros trabalhos desenvolvidos na UFMG têm introduzido a metodologia dos MC objetivando o aprimoramento dos métodos de ensino em diferentes disciplinas da área da saúde. Freire-Maia et al. (2011) avaliaram os impactos da utilização dos MC em disciplinas do curso de Odontologia da UFMG na percepção dos estudantes. Dentre os principais achados desse trabalho, destacamos que $42,3 \%$ dos alunos acreditam que os MC ajudam a criar relações entre conceitos, e favorecem a hierarquização do conhecimento para 25,5\% dos respondentes. Este trabalho evidencia também que os alunos, apesar da dificuldade que tiveram para se adaptar à metodologia, consideram os MC como ferramenta de estudo promissora. 69,4\% esperam que os MC sejam mantidos como estratégia de ensino e $73 \%$ avaliaram positivamente os MC como ferramenta para estruturar a abordagem de casos clínicos (FREIRE-MAIA et al., 2011).

No contexto específico do departamento de Morfologia e do setor de Anatomia Humana, Foureaux et al. (2015) avaliaram a implementação da metodologia dos MC como ferramenta didática no processo de ensino-aprendizagem da disciplina de Neuroanatomia Humana aplicada aos cursos de Fisioterapia e Terapia Ocupacional. Os principais achados desse estudo 
mostram que os MC auxiliaram de alguma forma na compreensão do conteúdo da disciplina de Neuroanatomia para 71,4\% dos alunos, e 31,6\% deles pretendiam continuar usando os MC em outras disciplinas do curso. Esse trabalho demonstrou também que o auxílio de monitores bolsistas, vinculados a um projeto de implementação dos MC no Departamento de Morfologia da UFMG, facilitou a elaboração dos MC para 48,1\% dos alunos.

\section{Método e Participantes}

O trabalho avaliou o uso da metodologia de MC sobre o rendimento dos alunos, considerando-se as notas parciais nas avaliações dos conteúdos teórico e prático de Anatomia Humana, e os resultados finais na disciplina. Os dados foram coletados no contexto da disciplina "Anatomia Aplicada à Fisioterapia", ofertada pelo Departamento de Morfologia do Instituto de Ciências Biológicas da Universidade Federal de Minas Gerais no período de março de 2011 a dezembro de 2013. Participaram do estudo 298 alunos matriculados na disciplina em questão, sendo que as notas dos alunos dos dois semestres letivos de 2011 foram utilizadas como controle, ou seja, foram semestres em que a metodologia ainda não havia sido implantada. Os grupos foram então divididos da seguinte forma: (1) grupo controle (sem MC): 2011.1 e 2011.2; (2) grupo MC: 2012.1, 2012.2, 2013.1; e, (3) grupo MC + monitoria: 2013.2.

Não houve critérios de exclusão. A introdução da metodologia de MC também não implicou alterações do funcionamento tradicional da disciplina, de forma que a disciplina manteve as mesmas características de horários, cenários de ensino, plano de ensino, distribuição de aulas e avaliações, bibliografia, recursos didáticos e estratégias pedagógicas básicas para abordagem dos conteúdos. Essas estratégias foram: incentivo à leitura do conteúdo previamente à realização das aulas; aulas expositivas com a utilização de recursos audiovisuais; demonstrações de aplicações clínicas dos temas expostos; aulas práticas com identificação de estruturas em peças anatômicas no laboratório e incentivo à discussão em grupos nas aulas práticas.

Conteúdos de Anatomia Humana, referentes ao $3^{\circ}$ e último módulo da disciplina, foram selecionados como temas para a construção de MC pelos alunos da disciplina nos dois semestres letivos de 2012 e $1^{\circ}$ semestre letivo de 2013. Os critérios para a seleção dos conteúdos foram: relevância do conteúdo na formação do graduando de Fisioterapia em função de sua aplicabilidade para o futuro profissional e o fato do tema ter sido abordado na disciplina também em 2011 (ano controle). Os alunos receberam, antes do início do $3^{\circ}$ módulo da disciplina, noções básicas para a construção de MC por meio de aula expositiva e atividades demonstrativas. Essas orientações básicas incluíram: definição dos termos utilizados nos MC; estrutura do mapa; uso de palavras de conexão com o propósito de transmitir o significado atribuído; importância das relações entre os conceitos; clareza e objetividade ao construir os próprios $\mathrm{MC}$, tornando-os de fácil compreensão por outras pessoas. Foi esclarecido que a devida interpretação de um MC depende das palavras de conexão, que permitem avaliar a adequada relação entre os conceitos apresentados no MC, evitando interpretações errôneas.

Após serem orientados sobre as noções básicas para a construção dos MC, os alunos foram instruídos a elaborar, individualmente, um MC referente a cada um dos nove temas selecionados e abordados anteriormente em aulas teóricas e práticas. Os alunos tiveram em média quatro semanas para a execução dessa tarefa. Após a entrega dos mapas na data acordada, cada 
aluno recebia os MC de outro colega da mesma turma, distribuído aleatoriamente, para que pudesse avaliar e emitir um parecer sobre tais mapas. Essa atividade foi utilizada pela equipe com o intuito de propiciar mais uma oportunidade de favorecer a aprendizagem significativa. Todos os alunos receberam as orientações sobre como avaliar um MC, baseadas nas seguintes diretrizes: representatividade do conteúdo do MC em relação aos temas abordados nas disciplinas, e criatividade, relacionada à estética do diagrama e às corretas relações entre os conceitos. Os alunos da disciplina de Anatomia Aplicada à Fisioterapia avaliaram os MC de seus pares em sala de aula, sob orientação do professor. Em seguida, o professor avaliou cada aluno, levando em consideração o MC construído pelo mesmo e o parecer de avaliação elaborado pelo aluno sobre o MC do colega.

No $2^{\circ}$ semestre de 2013, os alunos matriculados na disciplina realizaram os mesmos procedimentos descritos, no entanto, foram incluídos os temas dos dois primeiros módulos, o que resultou na construção de $30 \mathrm{MC}$ por cada aluno. Além disso, todos os alunos dispunham de monitorias semanais, com alunos de graduação que já haviam cursado a disciplina e eram bolsistas do projeto de ensino "Construção de mapas conceituais no ensino de disciplinas do Departamento de Morfologia”, financiado pelo Programa de Inovação e Qualidade no Ensino de Graduação (PIQEG) da Pró-Reitoria de Graduação da Universidade Federal de Minas Gerais. A Figura 1 apresenta um modelo de MC desenvolvido por um aluno.

Figura 1. Representação de um Mapa Conceitual (MC) desenvolvido por um aluno

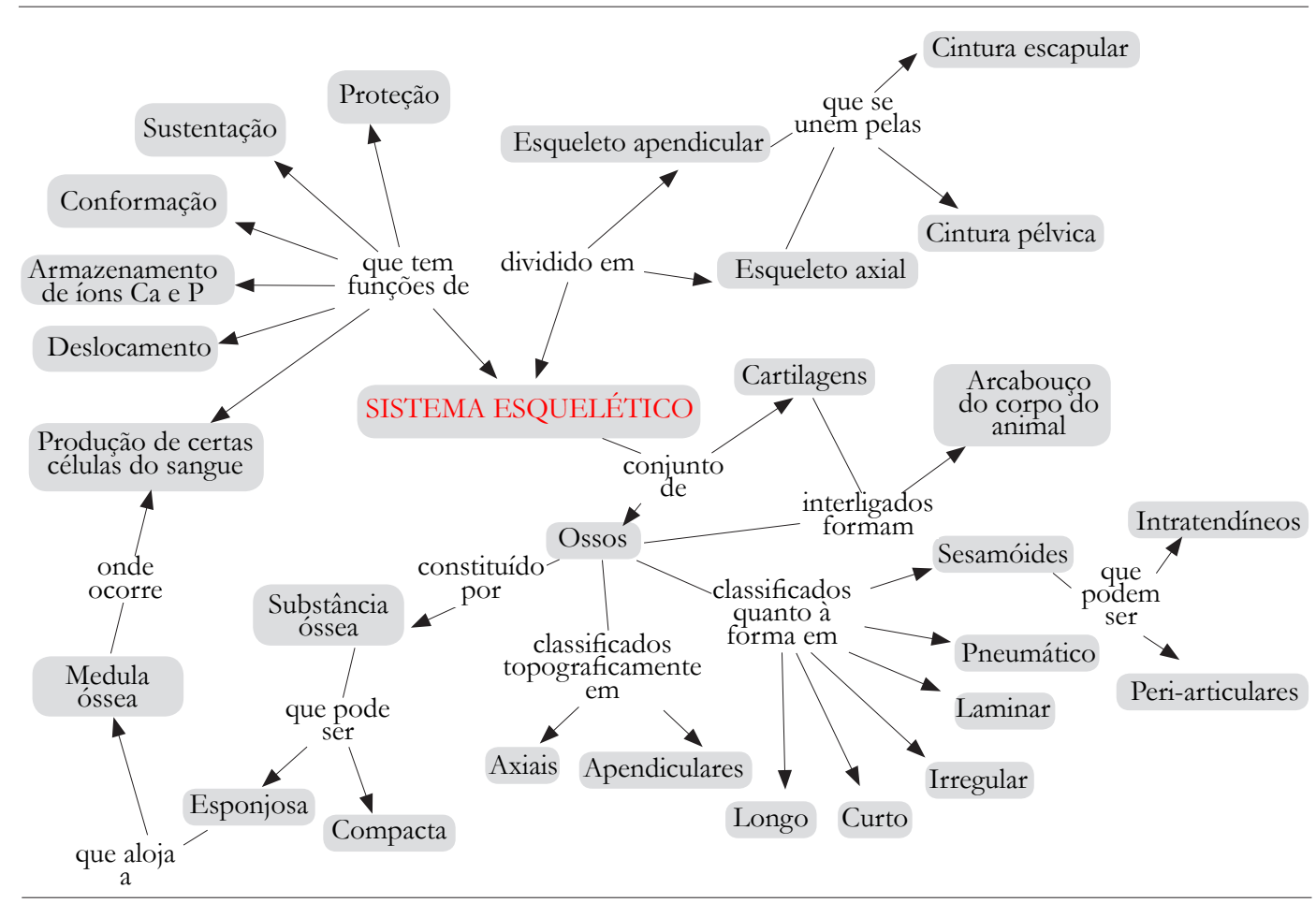

Fonte: elaborado pelos autores a partir de dados da pesquisa. 
A análise quantitativa comparou as médias das notas dos alunos nas avaliações teórica e prática (valor de cada avaliação $=15$ pontos) do $1^{\circ}$ módulo da disciplina, no qual os alunos ainda não utilizavam a metodologia dos $\mathrm{MC}$, com as do $3^{\circ}$ módulo, no qual os alunos estudaram desenvolvendo os MC. Também foi realizada a comparação das médias das notas dos alunos nas avaliações teórica e prática do $3^{\circ}$ módulo, obtidas em ambos os semestres de 2012 e no $1^{\circ}$ semestre de 2013, quando os alunos estudaram utilizando os MC sem monitorias, com aquelas obtidas no $2^{\circ}$ semestre de 2013, quando os alunos construíram MC contando com a orientação de monitores. Por fim, foi realizada a comparação entre a média das notas finais dos alunos que usaram MC nos dois semestres de 2012 e de 2013 e as médias das notas finais do ano de 2011 (ano controle), quando a estratégia de MC não havia sido implementada. A análise qualitativa foi baseada no relato dos alunos, coletado através de um questionário estruturado pelos autores, que abordou as seguintes questões: o que os alunos acharam dessa metodologia; se os alunos apresentaram alguma dificuldade na elaboração dos MC; se os MC auxiliaram no processo de aprendizagem do conteúdo e se as monitorias foram válidas no sentido de facilitar a compreensão dos estudantes sobre a metodologia MC.

\section{Análise estatística}

Os dados foram expressos como média \pm EPM. Foi realizado o teste de normalidade Shapiro-Wilk para todos os conjuntos de dados. Para os dados com distribuição normal, foi realizado o teste $t$ pareado. Para os dados com distribuição não normal, foram aplicados o teste de Wilcoxon ou o teste de Kruskal-Wallis seguido do teste de comparação múltipla de Dunn’s. Os dados com $\mathrm{p}<0,05$ foram considerados estatisticamente significativos. Todas as análises foram realizadas utilizando o programa GraphPad Prism 5.

\section{Resultados}

A análise das médias das notas finais dos alunos entre o $1^{\circ}$ semestre de 2011 e o $1^{\circ}$ semestre de 2013 demonstrou decréscimo dessas médias ao longo dos semestres (Figura 2) quando comparadas ao $1^{\circ}$ semestre de 2011 (semestre controle), sendo essa redução significativa no $1^{\circ}$ semestre de 2013 . Essa progressiva redução das médias finais foi revertida no $2^{\circ}$ semestre de 2013, quando o projeto de ensino dos MC foi aprimorado e teve sua equipe de trabalho aumentada, alcançando, inclusive, valores maiores que o semestre controle. A ampliação do projeto dos MC também foi capaz de promover uma redução significativa no índice de reprovação a partir do $2^{\circ}$ semestre de 2013 , considerando que no semestre anterior o aumento do número de reprovações atingiu valores significativamente maiores quando comparados ao semestre controle (Figura 3). 
Figura 2. Médias das notas finais dos alunos da disciplina de Anatomia Aplicada à Fisioterapia (2011-2013)

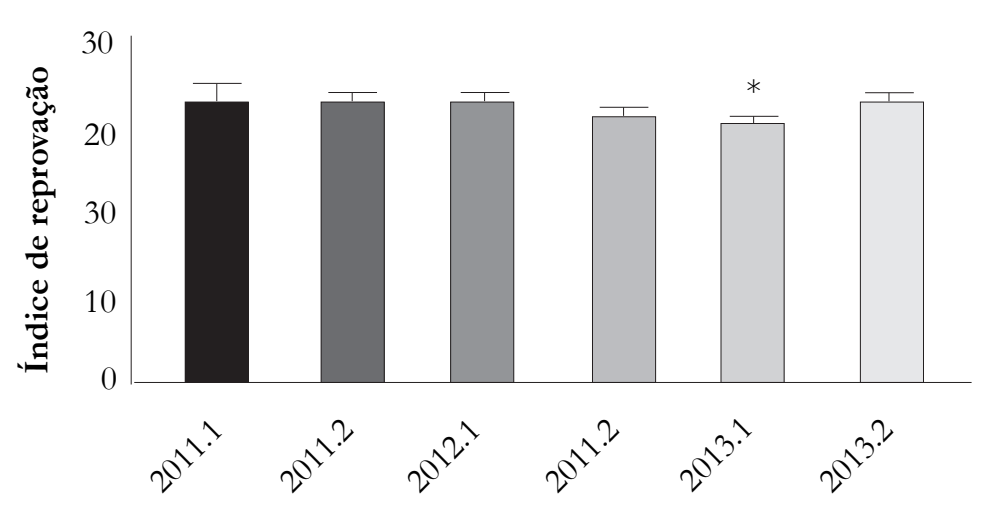

Semestres

$* \mathrm{p}<0,05$ quando comparado com o $1^{\circ}$ semestre de 2011 . Teste de Wilcoxon seguido do teste de comparação múltipla Dunn's.

Fonte: elaborado pelos autores.

Figura 3. Médias do índice de reprovação dos alunos da disciplina de Anatomia Aplicada à Fisioterapia (2011-2013)

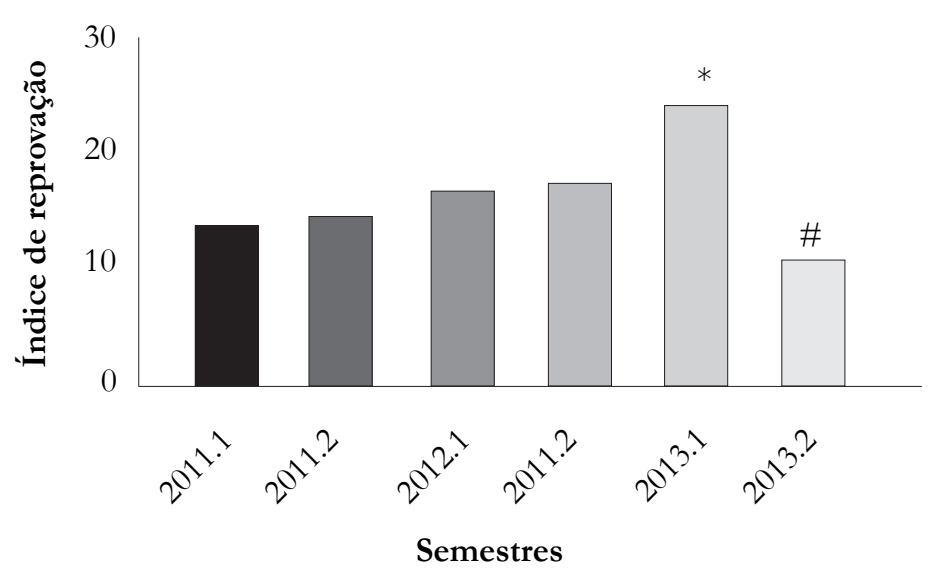

${ }^{*} \mathrm{p}<0,05$ quando comparado com o $1^{\circ}$ semestre de 2011 . \# $\mathrm{p}<0,05$ quando comparado com o $1^{\circ}$ semestre de 2013. Teste de Wilcoxon seguido do teste de comparação múltipla Dunn's.

Fonte: elaborado pelos autores. 
De uma forma geral, análises comparativas entre as notas dos $1^{\circ}$ e $3^{\circ}$ módulos de cada turma, a partir do $2^{\circ}$ semestre de 2011 , demonstraram melhor aproveitamento nas provas práticas e teóricas (valor máximo $=15,0$ pontos) do $3^{\circ}$ módulo, no qual os $\mathrm{MC}$ foram adotados como estratégia de estudo, com exceção do $2^{\circ}$ semestre de 2012 (Tabela 1). No $2^{\circ}$ semestre de 2011, observou-se um bom desempenho dos alunos na prova prática e um desempenho abaixo da média na prova teórica, considerando-se o $1^{\circ}$ módulo. Esse desempenho foi semelhante no $3^{\circ}$ módulo, em ambas as provas. No $1^{\circ}$ semestre de 2012 , a turma apresentou um baixo desempenho nas provas teórica e prática do $1^{\circ}$ módulo, apresentando notas no limite da média $(9,00)$ (Tabela 1). Após o início da utilização da metodologia dos $\mathrm{MC}$, no $3^{\circ}$ módulo foi observado um aumento significativo na média das notas, tanto na prova prática quanto na teórica. No $2^{\circ}$ semestre de 2012, a utilização dos MC não resultou em elevação da média das notas dos alunos quando comparou-se o desempenho do $1^{\circ}$ e $3^{\circ}$ módulos.

No $1^{\circ}$ semestre de 2013 , o desempenho dos alunos na prova prática do $1^{\circ}$ módulo foi inferior à média, mas apresentou significativa melhora no $3^{\circ}$ módulo, no qual os alunos elaboraram os MC. Já o desempenho dessa mesma turma na prova teórica do $1^{\circ}$ módulo estava dentro da média e não se alterou no $3^{\circ}$ módulo. No $2^{\circ}$ semestre de 2013 , no qual houve implementação das monitorias para apoio à elaboração dos MC, os alunos apresentaram desempenho abaixo da média na primeira prova prática, mas um bom resultado na primeira prova teórica. Esse desempenho foi significativamente aumentado em ambas as provas do $3^{\circ}$ módulo, ressaltandose que a média da terceira prova teórica foi a maior entre todas as turmas avaliadas (Tabela 1).

Considerando-se que os MC foram implementados no $1^{\circ}$ semestre de 2012, observou-se uma redução significativa do desempenho da turma do $2^{\circ}$ semestre de 2012 na prova prática. Já

Tabela 1. Análise comparativa entre as médias das notas dos alunos nos $1^{\circ}$ e $3^{\circ}$ módulos da disciplina de Anatomia Aplicada à Fisioterapia entre o $2^{\circ}$ semestre de 2011 e 2 ${ }^{\circ}$ semestre de 2013

\begin{tabular}{|c|c|c|c|c|c|c|}
\hline \multirow{3}{*}{ Provas } & \multicolumn{6}{|c|}{ Semestres } \\
\hline & \multicolumn{2}{|c|}{2011.2} & \multicolumn{2}{|c|}{2012.1} & \multicolumn{2}{|c|}{2012.2} \\
\hline & $\begin{array}{c}\text { Média } \pm \\
\text { E.PM. }\end{array}$ & Valor $\mathrm{p}$ & $\begin{array}{c}\text { Média } \pm \\
\text { E.PM. }\end{array}$ & $\begin{array}{c}\text { Valor } \\
\mathrm{p}\end{array}$ & $\begin{array}{c}\text { Média } \pm \\
\text { E.PM }\end{array}$ & $\begin{array}{c}\text { Valor } \\
\mathrm{p}\end{array}$ \\
\hline Prova Prática - $1^{\circ}$ módulo & $10,6 \pm 0,31$ & 0,465 & $8,9 \pm 0,38$ & $0,001 *$ & $9,4 \pm 0,35$ & 0,164 \\
\hline Prova Prática $-3^{\circ}$ módulo & $10,9 \pm 0,38$ & & $10,6 \pm 0,34$ & & $8,7 \pm 0,38$ & \\
\hline Prova Teórica - $1^{\circ}$ módulo & $8 \pm 0,43$ & 0,082 & $8,9 \pm 0,43$ & $0,022 *$ & $8,8 \pm 0,35$ & 0,576 \\
\hline Prova Teórica $-3^{\circ}$ módulo & $8,7 \pm 0,38$ & & $9,8 \pm 0,33$ & & $9,1 \pm 0,39$ & \\
\hline \multirow{3}{*}{ Provas } & \multicolumn{6}{|c|}{ Semestres } \\
\hline & \multicolumn{3}{|c|}{2013.1} & \multicolumn{3}{|c|}{2013.2} \\
\hline & Média \pm & E.PM & Valor $\mathrm{p}$ & Média & E.PM & Valor $\mathrm{p}$ \\
\hline Prova Prática - $1^{\circ}$ módulo & $7,6 \pm 0$ & & $0,0001 *$ & $8,3 \pm$ & ,34 & $0,0005^{*}$ \\
\hline Prova Prática $-3^{\circ}$ módulo & $9,3 \pm 0$ & & & 10,1 & 0,4 & \\
\hline Prova Teórica $-1^{\circ}$ módulo & $9,6 \pm 0$ & & 0,682 & $11 \pm$ &, 37 & $0,0184 *$ \\
\hline Prova Teórica $-3^{\circ}$ módulo & $9,5 \pm 0$ & & & $12,1 \pm$ & 0,21 & \\
\hline
\end{tabular}

$* \mathrm{p}<0,05$. Teste t pareado

Fonte: elaborado pelos autores. 
a turma do $2^{\circ}$ semestre de 2013, que teve o auxílio de monitores bolsistas para construir os MC, apresentou significativa melhora na média da prova prática do $3^{\circ}$ módulo quando comparada à turma do $2^{\circ}$ semestre de 2012 (Figura 4A). Com relação à prova teórica do $3^{\circ}$ módulo, a turma do $2^{\circ}$ semestre de 2013 também se destacou, apresentando a maior média entre as turmas avaliadas, com valores significativamente maiores em relação à turma do $1^{\circ}$ semestre de 2012 (Figura 4B).

Figura 4. Análise comparativa entre as médias das notas dos alunos nas avaliações prática (A) e teórica (B) do $3^{\circ}$ módulo da disciplina de Anatomia aplicada à Fisioterapia

A)

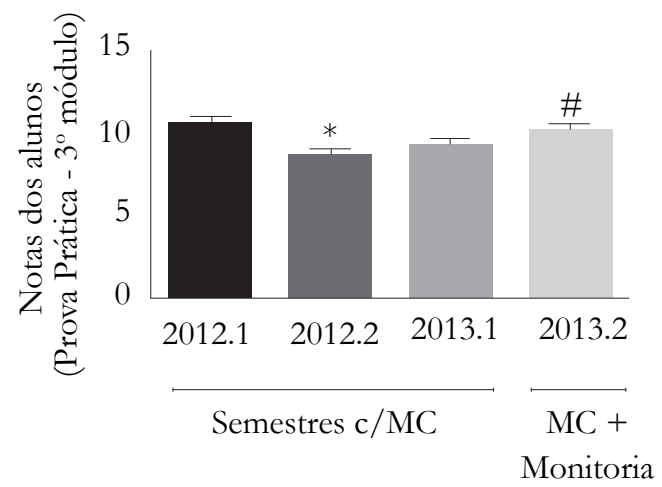

B)

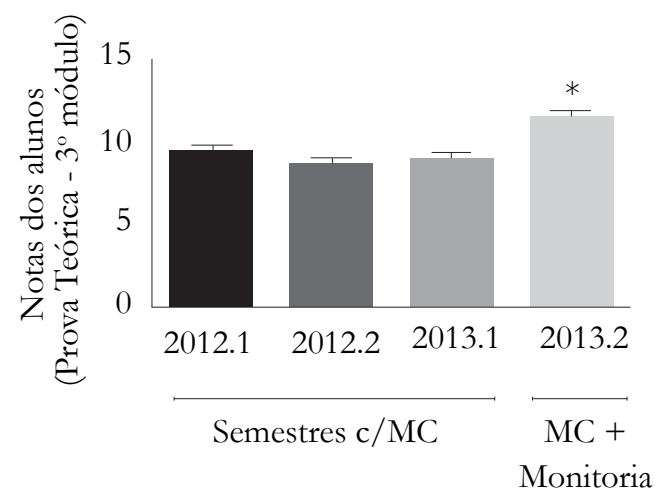

${ }^{*} \mathrm{p}<0,05$ quando comparado ao $1^{\circ}$ semestre de 2012; \# $\mathrm{p}<0,05$ quando comparado ao $2^{\circ}$ semestre de 2012 . Teste de Kruskal-Wallis seguido do teste de comparação múltipla Dunn's.

Fonte: elaborado pelos autores.

\section{Discussão}

Este trabalho foi desenvolvido para avaliar a eficácia dos MC como ferramenta de ação pedagógica no processo de ensino-aprendizagem da Anatomia Humana no curso de Fisioterapia da UFMG. Nosso principal resultado demonstra que os MC contribuíram para a diminuição do acentuado índice de reprovação, observado nos últimos anos, no contexto da disciplina de Anatomia Aplicada à Fisioterapia, integrante da matriz curricular do curso de Fisioterapia da UFMG.

O avanço tecnológico observado nas últimas décadas reflete de forma bastante incisiva no cenário educativo, uma vez que as transformações tecnológicas possibilitam que uma pessoa busque o conhecimento de forma rápida e acessível, a qualquer hora, tempo e velocidade (PIAZZA; CHASSOT, 2011). Os aspectos positivos proporcionados pelo avanço da ciência e da tecnologia são incontestáveis. No entanto, é possível perceber uma acentuada divisão entre aqueles que conseguem se beneficiar desse avanço e aqueles que se encontram às margens dele (MALAFAIA; RODRIGUES, 2011). Neste âmbito, o modelo educacional tradicionalmente ado- 
tado pelas instituições de ensino parece não ser mais suficiente para atender um público com tanta imersão nessa era tecnológica e interativa. Para superar algumas dessas dificuldades, no estudo de Freire e Fernandez (2015), professores apontam a importância da dedicação ao planejamento das ações didáticas, bem como o esforço pessoal e a aprendizagem propiciada pela experiência.

Segundo Pedrancini et al. (2007), os principais motivos que dificultam a aprendizagem significativa de conceitos e processos biológicos estão relacionados ao ensino fragmentado e conservador, restringindo o aluno a cumprir tarefas repetitivas sem sentido ou significado, de modo a valorizar somente a reprodução do conhecimento e, consequentemente, formando apenas repetidores. Especificamente, no que diz respeito ao estudo da Anatomia Humana, tal aspecto ainda pode ser agravado pela necessidade real de memorização de muitas estruturas anatômicas pelos alunos. Assim, é possível que esta peculiaridade, que envolve o estudo da Anatomia Humana, somada à mudança no perfil dos alunos, decorrente do acesso fácil e virtual ao conhecimento, possam ter contribuído para a redução do desempenho dos alunos nas disciplinas de Anatomia Humana no decorrer dos últimos anos.

Com base nessa observação e na urgente necessidade de tentar mudar essa conjuntura, a partir do $1^{\circ}$ semestre de 2012 foi implementada a utilização dos MC nas turmas da disciplina Anatomia aplicada à Fisioterapia. Durante todo o ano de 2012 e $1^{\circ}$ semestre de 2013 avaliamos essa ferramenta de ação pedagógica por meio das notas dos alunos nas provas, considerando módulos da disciplina nos quais os MC foram utilizados ou não. Diante da melhora significativa do aproveitamento dos alunos nas provas prática e teórica já no $1^{\circ}$ semestre de 2012 , um projeto de ensino sistematizado foi proposto e implementado em 2013, com o apoio financeiro da Universidade. A aprovação desse projeto possibilitou agregar oito monitores bolsistas, tutores e professores, além de ter possibilitado a aquisição de recursos materiais, como uma sala e computador para uso exclusivo do projeto. Todos os envolvidos com o projeto, principalmente os monitores que atuariam no atendimento direto aos alunos, receberam treinamento durante o $1^{\circ}$ semestre de 2013 , sendo que no $2^{\circ}$ semestre de 2013 , essa ferramenta de ação pedagógica foi levada aos alunos de forma mais incisiva. A partir desse treinamento, os monitores estavam aptos a acompanhar de forma mais individual as dificuldades específicas de cada aluno, orientando-os quanto à construção dos seus MC.

No primeiro contato com essa ferramenta, apenas alguns alunos consideraram complexa a construção de $\mathrm{MC}$, relatando a dificuldade de usar as palavras de ligação e diferenciar um MC de um organograma. De forma geral, foi possível constatar que todos os alunos apresentavam evolução na elaboração e estruturação dos seus MC no decorrer do tempo, à medida que se familiarizavam com o uso da ferramenta. No entanto, os alunos que procuravam com maior assiduidade a assistência dos monitores conseguiram construir MC mais estruturados e com maior facilidade que os alunos que optavam por não frequentar as monitorias. Portanto, a implementação do projeto, especialmente pela possibilidade das monitorias, contribuiu ainda mais para melhorar o desempenho dos alunos, visto que no $2^{\circ}$ semestre de 2013 foi obtido um maior resultado nas provas teórica e prática, considerando os seis semestres anteriores. Isso refletiu na média final dos alunos e reduziu, significativamente, o índice de reprovação dos mesmos. Nossos resultados confirmam os achados de Foureaux et al. (2015) que observaram, de acordo com a percepção dos alunos, que a monitoria facilitou a elaboração dos MC. De maneira oposta, Freire-Maia et al. (2011) observaram que o auxílio de monitores bolsistas não foi considerado importante pelos alunos, que afirmaram ter aprendido a trabalhar com os MC 
sozinhos ou com o auxílio de colegas. Esse contraste pode ser explicado, em parte, pelas diferentes características das disciplinas em que a metodologia dos MC foi implementada ou pelo diferente nível de maturidade dos alunos, uma vez que no estudo de Foureaux et al. (2015), a turma avaliada estava no $2^{\circ}$ período, e no trabalho de Freire-Maia et al. (2011), a metodologia foi implementada em disciplinas do $4^{\circ}$ ao $8^{\circ}$ período.

O presente trabalho demonstra que a utilização dos MC constituiu uma estratégia pedagógica promissora dentro do contexto específico do ensino da Anatomia Humana, que tem três formas distintas e tradicionais de abordagem didática: texto, atlas e acervo, que inclui cadáveres, peças e modelos, além da aula expositiva. Com a metodologia de MC, foi possível ir além da abordagem tradicional, há muito praticada, visto que possibilitamos aos alunos a construção e integração de conhecimentos. Isso favorece o desenvolvimento do pensamento holístico, que por sua vez, pode contribuir para o desenvolvimento do pensamento crítico. $\mathrm{O}$ pensamento crítico é entendido como raciocínio cuidadoso, deliberado e focalizado em resultados, ou seja, é um processo intencional de julgamento que leva em consideração evidências, métodos e critérios (ALFARO-LEFEVRE, 2010; BITTENCOURT et al., 2013).

Além da melhora na média final dos alunos, esses ainda relataram maior satisfação em relação ao aprendizado, o que também pode ter contribuído, de forma indireta, para o aumento no índice de aprovação dos alunos na disciplina. Corroborando nossos dados, Pereira et al. (2007) também verificaram que os alunos demonstraram maior satisfação e maior empenho na disciplina de Anatomia Humana do curso de Biologia da Universidade Pompeu Fabra em Barcelona, quando os professores utilizaram recursos menos tradicionais, tais como recursos audiovisuais, internet, programas e outros materiais de multimídia.

O melhor desempenho dos alunos, a partir da utilização dos MC, pode estar relacionado ao fato dos $\mathrm{MC}$ apresentarem características que favorecem a aprendizagem significativa, tais como: (a) ser centrado no aluno e não no professor; (b) atender ao desenvolvimento de destrezas e não se limitar apenas à memorização da informação por parte do estudante; (c) pretender o desenvolvimento de todas as dimensões da pessoa e não apenas as intelectuais (MOREIRA, 2006; ONTORIA, 2005). Soma-se a isso, o fato do uso de organizadores gráficos permitirem o duplo processamento cognitivo do conteúdo: expresso por meio da linguagem e de imagens (CICUTO; MENDES; CORREIA, 2013; SWELLER; KALYUGA, 2011), o que favorece ainda mais a solidificação e construção do conhecimento.

A elaboração do parecer sobre o MC do colega proporcionou a oportunidade de os alunos se ensinarem reciprocamente, por meio da discussão dos conteúdos. Através dos relatos dos alunos, foi possível perceber que a elaboração do parecer contribuiu para ampliar a sedimentação do conhecimento. Menezes (2009) já havia afirmado que atividades coletivas, mais estruturadas que as aulas expositivas, exploram a inteligência interpessoal, possibilitando aos alunos autonomia para aprender e ensinar uns com os outros, o que pode maximizar as potencialidades individuais e favorecer o aprendizado (GARDNER, 1995). Pizza e Chassot (2011) também enfatizam o chamado ensino recíproco entre pares, e afirmam que esta aprendizagem cooperativa ilustra circunstâncias em que os alunos desempenham papéis de aluno e professor. Para estes autores, ao assumirem a responsabilidade de ensinar aos seus pares, os alunos não apenas melhoram a sua compreensão e comprometimento, como também aprimoram habilidades de comunicação, trabalho em equipe, liderança, confiança e respeito. Pizza e Chassot (2011) verificaram que o ensino recíproco entre pares promoveu uma melhora de $97 \%$ na retenção 
do ensino, e 92\% na melhora da capacidade de comunicação, tanto na aula teórica quanto na aula prática. Nesse contexto, professores relataram a importância de uma relação de troca de experiência e muito diálogo, e ressaltaram a necessidade de não restringir os alunos a uma relação de submissão, visto que podem compor juntos a configuração do campo da docência no Ensino Superior (FREIRE; FERNANDEZ, 2015).

Contudo, apesar dos resultados promissores encontrados, identificamos algumas limitações do estudo que já estão sendo corrigidas para propiciar um aproveitamento cada vez maior da metodologia dos MC por docentes e, principalmente, pelos discentes. O primeiro ponto a ser melhorado é a investigação mais aprofundada da percepção dos alunos, tão importante quanto avaliar o desempenho acadêmico dos mesmos. Esse feedback dos alunos é fundamental para que a metodologia possa ser sempre aprimorada, objetivando um melhor aproveitamento da mesma pelos discentes. Outro ponto a ser mais explorado é o perfil dos participantes, que precisa ser mais bem detalhado. Além disso, em estudos futuros, se faz necessário desenvolver mais estratégias para investigar se de fato houve favorecimento à ocorrência da aprendizagem significativa, focando na análise de significados ensinados e aprendidos.

Em conjunto, nossos resultados demonstram, de maneira expressiva, que a metodologia dos MC tem sido gradualmente compreendida e incorporada pelos alunos como ferramenta de estudo, o que tem propiciado uma evolução considerável no desempenho acadêmico dos mesmos. Considerando que os MC começaram a ser adotados como estratégia didática no $1^{\circ}$ semestre de 2012, em pouco menos de dois anos já foi possível observar melhora no desempenho dos alunos. Além disso, considerando a tendência para o aumento no índice de reprovação observada no decorrer dos anos, cujos valores se tornaram estatisticamente significativos no $1^{\circ}$ semestre de 2013, constatamos uma redução do índice de reprovação na disciplina de Anatomia Aplicada à Fisioterapia no $2^{\circ}$ semestre de 2013. Assim, podemos inferir que a sistematização desta metodologia, principalmente com o auxílio dos monitores no $2^{\circ}$ semestre de 2013 , teve grande influência nesse processo.

\section{Considerações finais}

É consenso, entre educadores e pesquisadores, a importância de uma educação de qualidade na formação e preparação dos discentes para a sociedade atual e, dentro dessa esfera, o ensino da Anatomia Humana tem se tornando cada vez mais desafiador. Neste estudo, demonstramos que uma estratégia facilitadora de aprendizagem significativa, baseada na elaboração de MC, foi eficaz em proporcionar a melhora no desempenho dos alunos na disciplina de Anatomia Aplicada à Fisioterapia, ofertada na UFMG. Além disso, essa proposta metodológica foi capaz de reverter o progressivo aumento do índice de reprovação observado nos últimos anos.

Nossos achados foram promissores, mas ainda há muito a ser realizado. A reflexão sobre as posturas e estratégias tradicionais de ensino é imprescindível, se pretendemos uma educação de qualidade alinhada e voltada para as demandas do mundo contemporâneo. Essa reflexão deve considerar a eficácia das estratégias pedagógicas na mediação do aprendizado de jovens inseridos no contexto atual de conhecimento, cuja imersão em recursos tecnológicos de fácil acesso propiciam maneiras criativas e variadas de obter e processar as informações. O desafio é assumir e implementar as mudanças necessárias para essa educação de qualidade. 
Silva, J. H.; Foureaux, G.; Sá, M. A.; Schetino, L. P. L.; Guerra, L. B.

\section{Agradecimentos}

Os autores agradacem à PROGRAD (Pró Reitoria da Graduação) da UFMG, pela concessão das bolsas aos monitores, à Rede de Desenvolvimento de Práticas de Ensino Superior (GIZ), pelo apoio com as salas virtuais da plataforma Moodle da UFMG e aos alunos, que colaboraram para o desenvolvimento e geração dos dados e dos resultados desse trabalho.

\section{Referências}

ALFARO-LEFEVRE, R. Aplicação do processo de enfermagem: uma ferramenta para o pensamento crítico. Porto Alegre: Artmed, 2010.

ALLEN, D.; TANNER, K. Infusing active learning into the large-enrollment biology class: seven strategies, from the simple to complex. Cell Biology Education, Bethesda, v. 4, n. 4, p. 262-268, 2005.

BITTENCOURT, G. K. G. D. et al. Mapas conceituais no ensino de pós-graduação em enfermagem: relato de experiência. Revista Gaúcha de Enfermagem, Porto Alegre, v. 34, n. 2, p. 172-176, 2013. Disponível em: < https://doi.org/10.1590/S1983$14472013000200022>$. Acesso em: 24 jan. 2018.

BRAGA, M. M.; PEIXOTO, M. C. L.; BOGUTCHI; T. F. A evasão no ensino superior brasileiro: o caso de UFMG. Avaliação: revista de rede de avaliação institucional da educação superior, Campinas, v. 8, n. 3, p. 161-189, 2003.

BRANSFORD, J. D.; BROWN, A. L.; COCKING, R. R. How people learn: brain, mind, experience, and schools. Washington: National Academies Press, 1999.

CAÑA, A. et al. A summary of literature pertaining to the use of concept mapping techniques and technologies for education and performance support. Pensacola: Institute for Human and Machine Cognition, 2003.

CICUTO, C. A. T.; MENDES, B. C.; CORREIA, P. R. M. Nova abordagem para verificar como os alunos articulam diferentes materiais instrucionais utilizando mapas conceituais.

Revista Brasileira de Ensino de Física, São Paulo, v. 35, n. 3, p. 3402, 2013. Disponível em: <https://doi.org/10.1590/S1806-11172013000300019>. Acesso em: 24 jan. 2018.

DI DIO, L. J. A. Tratado de anatomia aplicada. São Paulo: Poluss, 1998.

DIPLOMAÇÃO, retenção e evasão nos cursos de graduação em instituições de ensino superior públicas. Avaliação: Revista de rede de avaliação institucional da educação superior. Campinas, v. 1, n. 2, p. 55-65, 1996.

FEDERATIVE COMMITTEE ON ANATOMICAL TERMINOLOGY. Terminologia anatomica. Stuttgart: Georg Thieme, 1998.

FORNAZIERO, C. C. et al. Integração do corpo humano e meio ambiente. Revista Brasileira de Educação Médica, Rio de Janeiro, v. 34, n. 2, p. 290-297, 2010. Disponível em: <https://doi.org/10.1590/S0100-55022010000200014>. Acesso em: 24 jan. 2018. 
FOUREAUX, G. et al. Mapas conceituais: uma valiosa ferramenta didática para o ensino da disciplina de neuroanatomia humana. Espacios, Caracas, v. 36, n. 14, p. E-2, 2015.

FREIRE, L. I. F.; FERNANDEZ, C. O professor universitário novato: tensões, dilemas e aprendizados no início da carreira docente. Ciência \& Educação, Bauru, v. 21, n. 1, p. 255-272, 2015. Disponível em: <https://doi.org/10.1590/1516-731320150010016>. Acesso em: 24 jan. 2018.

FREIRE-MAIA, F. B. et al. Avaliação da utilização dos mapas conceituais em disciplinas do curso de odontologia da UFMG na percepção dos estudantes. Revista Docência do Ensino Superior, Belo Horizonte, v. 1, p. 34-48, 2011. Disponível em: <https:/ / seer.ufmg. br/index.php/rdes/article/view/978/743>. Acesso em: 24 jan. 2018.

GARDNER, H. Inteligências múltiplas: a teoria na prática. Porto Alegre: Artmed, 1995.

GOMES, A. P. et al. O papel dos mapas conceituais na educação médica. Revista Brasileira de Educação Médica, Rio de Janeiro, v. 35, n. 2, p. 275-282, 2011. Disponível em: <https://doi.org/10.1590/S0100-55022011000200018>. Acesso em: 24 jan. 2018.

LOBO, M. B. C. M. Panorama da evasão no ensino superior brasileiro: aspectos gerais das causas e soluções. ABMES Cadernos, Brasília, n. 25, p. 9-58, 2012. Disponível em: $<$ https://www.abmes.org.br/arquivos/publicacoes/Cadernos25.pdf>. Acesso em: 24 jan. 2018.

MALAFAIA, G.; RODRIGUES, A. S. L. O uso da teoria das inteligências múltiplas no ensino da Biologia para alunos do ensino médio. SaBios: revista de saúde e biologia, Campo Mourão, v. 6, n. 3, p. 8-17, 2011. Disponível em: <http://revista.grupointegrado.br/revista/ index.php/sabios2/article/view/762>. Acesso em: 24 jan. 2018.

MENEZES, L. C. O aprendizado do trabalho em grupo. Nova Escola, São Paulo, n. 222, 2009. Disponível em: <https://novaescola.org.br/conteudo/605/o-aprendizado-dotrabalho-em-grupo >. Acesso em: 24 jan. 2018.

MOREIRA, M. A. A teoria da aprendizagem significativa e sua implementação em sala de aula. Brasília: Universidade de Brasília, 2006.

MOREIRA, M. A. Al final, que és aprendizaje significativo? Qurriculum, La Laguna, v. 25, p. 29-56, 2012.

MOSLEY, M.; LYNCH, J. Uma história da ciência: experiência, poder e paixão. Rio de Janeiro: Zahar, 2011.

NOVAK, J. D. The promise of new ideas and new technology for improving teaching and learning. Cell Biology Education, Bethesda, v. 2, n. 2, p. 122-132, 2003.

NOVAK, J. D.; GOWIN, D. B. Learning how to learn. Boston: Cambridge University Press, 1984.

NOVAK, J. D.; WANDERSEE, J. H. Perspectives on concept mapping. Journal of

Research in Science Teaching, Hoboken, v. 27, n. 10, p. 921-1075, 1990. 
Silva, J. H.; Foureaux, G.; Sá, M. A.; Schetino, L. P. L.; Guerra, L. B.

ONTORIA, A. Mapas conceituais: uma técnica para aprender. São Paulo: Loyola, 2005.

PEDRANCINI, V. D. et al. Ensino e aprendizagem de biologia no ensino médio e a apropriação do saber científico e biotecnológico. Revista Electrónica de Enseñanza de las Ciencias, Vigo, v. 6, n. 2, p. 299-309, 2007.

PEREIRA, J. A. et al. Effectiveness of using blended learning strategies for teaching and learning human anatomy. Medical Education, Chichester, v. 41, n. 2, p. 189-195, 2007.

PIAZZA, B. L.; CHASSOT, A. I. Anatomia humana, uma disciplina que causa evasão e exclusão: quando a hipótese principal não se confirma. Ciência em Movimento, Porto Alegre, v. 14, n. 28, p. 45-59, 2011. Disponível em: <https://doi.org/10.15602/1983-9480/ cmedh.v14n28p45-59>. Acesso em: 24 jan. 2018.

PRIM, A. L.; FÁVERO, J. D. Motivos da evasão escolar nos cursos de ensino superior de uma faculdade na cidade de Blumenau. E-Tech: tecnologias para competitividade industrial, Florianópolis, n. 3, p. 53-72, 2013. (Edição especial). Disponível em: <https://doi. org/10.18624/e-tech.v0i0.382>. Acesso em: 24 jan. 2018.

RUIZ-MORENO, L. et al. Mapa conceitual: ensaiando critérios de análise. Ciência $\boldsymbol{\&}$ Educação, Bauru, v. 13, n. 3, p. 453-463, 2007. Disponível em: < https://doi.org/10.1590/ S1516-73132007000300012>. Acesso em: 24 jan. 2018.

SWELLER, J. P.; KALYUGA, A. S. Cognitive load theory. New York: Springer, 2011.

VEKIRI, I. What is the value of graphical displays in learning? Education Psychology Review, New York, v. 14, n. 3, p. 261-312, 2002.

WILLERMAN, M. H. The concept map as an advance organizer. Journal of Research in Science Teaching, Hoboken, v. 28, n. 8, p. 705-711, 1991. 